\title{
Research Use of Patented Technologies
}

\begin{abstract}
Ann Monotti
A common pattern for scientific research involves experimentation with existing theories, products and processes with the aim of discovering something new. Some of the products and processes that researchers use or investigate may be patented, but the user may be ignorant of this fact. There is therefore a risk that the research may involve unauthorised use of patented inventions in a way that infringes a patent holder's exclusive rights.

At the end of the project, the research outcomes may include patentable inventions that may be worthy of commercial exploitation. There is potential for infringement of another's rights here too, either because a patented invention is necessary for the production of the new inventions, or because the new results intrude into an area of invention for which patents have been granted to others. The potential for infringement of patent rights means that universities must, and do, have risk management procedures in place when they seek to exploit commercially any intellectual property (IP).

However, risk management may also be relevant during the research process itself. Under the Australian Research Council et al (ARC, 2001) National Principles of Intellectual Property Management for Publicly Funded Research (National Principles), when the research is funded with a national competitive grant, the grant conditions impose certain responsibilities upon universities at the commencement of the research to have procedures in place to protect the freedom to operate in the respective fields of research. In particular, National Principle 5 (NP5) is in the following terms:
\end{abstract}

Assessment of existing IP: Institutions will have procedures in place to guide researchers in assessing the existing IP in the field that is likely to affect their research in order to determine their freedom to operate in that field of research.

This article examines the obligations that universities assume under NP5 when their researchers win national competitive grants. It identifies the problems that they face with compliance both before and during the research project. The article concludes that universities should review, and if necessary, upgrade internal practices for practical risk management as a way of dealing with the obligations that NP5 imposes. It also recommends that the ARC and other national research councils should be proactive in initiating a review of NP5 and its intended purpose. It may be necessary for universities to be proactive in initiating this review.

Ann Monotti is Associate Professor, Faculty of Law, Monash University. 


\section{Infringement Exemption for Experimental Use}

Examination of the obligations imposed by NP5 relies upon some understanding of the extent to which researchers can use patented inventions in their research without infringement. Therefore, some background is necessary here. As noted by the Advisory Council on Intellectual Property (ACIP), the grant of a patent provides powerful rights for the patent holder, which are so broad as to cause consternation that 'patent rights may be inhibiting research and development, particularly in biotechnology' (ACIP, 2004:Introduction). The Patents Act 1990 (Cth) (Patents Act), in contrast with the position in the UK under the Patents Act 1977, contains no express exemption or defence from infringement for research, experimental, instructional or private use of a patented invention. The absence of an express provision means that these activities will infringe the patent unless they are outside the scope of the patent holder's exclusive rights or unless the common law provides a defence to infringement.

For many years, Australian researchers had widely assumed that basic research without commercial direction would not infringe patents which covered the area in which they researched (Blanco White, 1974:3-216; Ricketson, 1984:para 50.21, 50.22, and 50.24; Lahore, Dwyer and Dufty, 1996: para 18 and 340; ALRC, 2004:13.37; Dennis, 2003; Nicol, 2003:218). Licences to relevant patents were thought to be required only when researchers embarked upon a commercial path. Whether or not this reflected the accurate position in law, patent holders appeared to accept that basic research could proceed without the threat of infringement proceedings. However, the reports from two inquiries, Genes and Ingenuity: Gene Patenting and Human Health, by the Australian Law Reform Commission (ALRC, 2004), and Patents and Experimental Use by ACIP (2005), cast doubt on the existence and scope of any experimental use exemption of this kind. Both recommended a change to the law to clarify the position.

This paper is not concerned with the assessment of the existence or otherwise of an experimental use exemption at common law (see Monotti, 2006). Nor is the paper concerned with whether the lack of an express experimental research exemption in the Patents Act 1990 (Cth) actually impedes research. (ALRC, 2004:13.41) Rather, the uncertainty in this area is relevant to the ability of universities to design their risk management procedures and in particular to provide guidance to their researchers for avoiding patent infringement.

\section{Obligations Under National Principles}

The principal sources of funds for university research are: international competitive grants; national competitive grants such as the National Health and Medical Research Council (NHMRC) and the Australian Research Council (ARC); industry funding; and university internal grants. Both the ARC and the NHMRC purport to influence exploitation of intellectual property that is created with their funding through the National Principles of Intellectual Property 
Management for Publicly Funded Research (2001). The purpose underlying the development of the National Principles is:

to assist researchers, research managers and their research institutions, in ensuring that they have access to best practices for the identification, protection and management of IP, and therefore, to maximise the national benefits and returns from public investment in research.

Where appropriate, the National Principles seek to improve commercial outcomes from publicly funded research (ARC, 2001:Foreword). The receipt of public funds through the process of national competitive grants requires compliance with these National Principles. For example, the ARC Discovery Grant Funding Rules for Funding commencing in 2007 contain in clause 11.4.4:

Except with written approval from the ARC, all Proposals and ARCfunded research projects must comply with the National Principles of Intellectual Property Management for Publicly Funded Research (available at http://www.arc.gov.au) and accord with any intellectual property policies of the researchers' organisations.

These latest rules are more flexible than those which applied in 2006 in that they allow for negotiation of these principles. Clause 11.4 in those rules stated:

Applicants must agree to comply with the National Principles of Intellectual Property Management for Publicly Funded Research (available at www.arc.gov.au) and act in accordance with any intellectual property policies of the applicant's organisation.

There are nine principles, but only NP5 is relevant here. Its requirement for universities to have procedures for a 'freedom to operate' (FTO) analysis is difficult to apply prior to commencement of research, or even during the research project, due to the uncertainty surrounding non-infringing research uses of a patented invention as well as a variety of other reasons that are discussed below.

\section{The Concept of 'Freedom to Operate'}

The concept of 'freedom to operate' is a form of risk management and is familiar to those involved in research and development within commercial organisations. A vigilant corporation ensures that it conducts appropriate searches for patents that may affect any new line of research. Other corporations, particularly small to medium enterprises (SMEs), may not search for patents before commencing research but may negotiate licences or use other strategies when they later decide to commercialise a new product or technology.

FTO analysis is particularly important for companies that conduct research and market products in sectors where patenting is extensive. Specialist companies and some national patent offices provide services to perform an FTO analysis. 
When patents block commercial development, the most common strategies for a company to adopt are licensing-in the technology, cross licensing, working around the invention or establishing patent pools (Burrone, undated). Ideally, they have an existing patent portfolio that can be used for bargaining. In a recent example of a new form of cross licensing in electronics, IBM, Sony and Philips joined forces with the two largest Linux software distributors to create a company - Open Innovation Network - for sharing Linux patents, royalty-free (Auchard, 2005).

\section{Monash Survey 2005}

In the process of discussing the difficulties that NP5 imposes upon universities, this article draws on the results of a survey administered at Monash University in September 2005 to 500 researchers in the Faculty of Medicine, Nursing and Health Science. The purpose of the survey was to obtain information on access to tangible research materials in biomedical research within this faculty. These could be patented materials, but could equally be materials that have no intellectual property protection. An accompanying explanatory letter asked researchers to identify the relevance of the survey to them. It was relevant only if they created or discovered materials useful for research purposes, used materials or supplied others with materials for research purposes. Recipients were asked to return the survey if not relevant to them. 'Materials' were defined to include antibodies, cell lines, cloned animals, plasmids, vectors, genes, software, databases, tissue (animal and human) and fluids (animal and human). The aims of the survey were explained in the following terms:

There is anecdotal evidence that the conditions of access to research materials inhibit research within universities. The first aim of this survey is to test this proposition within the Medicine, Nursing and Health Sciences at Monash University.

The second aim of this survey is to improve access:

- nationally through recommended policies and standard conditions

- within Monash through initial data collection for a register of research materials

The ultimate aim of the research project is to investigate the balance of rights between intellectual property owners, research users and the public.

Responses were anonymous. Over 45 per cent of respondents returned surveys: 122 (24.4\%) completed - the rest were returned as not relevant.

\section{Access to Patented Materials and Processes}

Access to patented materials and processes used in research may be with or without the licence of the patent holder. The licence of the patent holder is 
implied from the purchase on the open market of goods such as chemicals and equipment. As a general proposition, the patent holder is rewarded by the purchase price of the goods and makes no claims to outcomes that arise from use of the patented product. In other cases, access may be available only after direct negotiation with the patent holder. For example, not all tangible research materials (TRMs) are necessarily freely available for purchase but may be made available by the patent holder on conditions that are contained in an agreement that is commonly referred to as a Materials Transfer Agreement (MTA).

An MTA governs the transfer of materials between two organisations, when the recipient intends to use them for research purposes. It defines the rights of both parties with respect to the materials and any derivatives. An MTA is used to govern the transfer of biological and other materials such as chemical compounds, and even some types of software. Academic and research institutions are likely to be both suppliers and users of TRMs. In the US, the National Institutes of Health (NIH) has expended considerable effort to provide standard MTAs to assist efficient transfer of TRMs. This has not happened in Australia to date (NIH 1998; Monotti 2006b). The lack of standard agreements and the complexity of some of these arrangements can delay researchers in obtaining the materials they require to commence or continue their research. This can in turn influence the effectiveness of procedures that universities develop to reduce the risks of patent infringement.

It is not known how, or indeed if, universities comply with NP5 before a research funding application is submitted or before funded research commences. If the research requires tangible materials that embody a patented invention, it is likely these materials are not to accessible without the prior execution of an MTA. In practice, compliance with NP5 is possible because the materials' owner will disclose their protected status to a university, which can then apply procedures to review any MTA. In this regard, universities can ensure that the MTA protects the researchers not only in using the material in their current research, but also any intellectual property created with its use in subsequent research. The existence of an experimental use exemption may influence a university's negotiating position but the MTA will replace any common law exemption that exists. The principles applicable here are not limited to the use of tangible materials in publicly funded research and may also apply in relation to industry funded research.

Not all uses of a patented invention require direct contact with the patent holder. In some cases, they will still come from an authorised source so that compliance with NP5 remains possible. For example, patented materials may be obtained from a member of a collaborative research project with prior authorisation from the patent holder. In this case, it is likely the collaborator would know the patented status of the materials and that the collaborative agreement enables their use by all collaborators. However, it is conceivable that a researcher may obtain patented materials or details of how to perform a patented process from a published patent specification or other documentary disclosure. The supply could also arise pursuant to usual scientific community conventions where materials are exchanged for purposes of relationship building, goodwill, or 
in return for acknowledgment or co-authorship on publications. Informal exchange is common. As one respondent to the Monash Survey commented:

A great deal of exchange between researchers is informal, and is usually of the kind that is to help someone out by providing materials they haven't got, can't get, or by exchanging them brings the two groups into greater collaborative contact.

It is not inconceivable that some of this material may be patented or fall within the scope of a patent. Such unlicensed use may occur deliberately, such as where the patented invention is not readily available on a licensed basis in an anonymous market, or through ignorance that the use requires authorisation. Informal supply may increase when researchers experience frustration and delays in obtaining access to materials after having previously followed the risk management procedures that universities implement to control informal sharing of materials.

\section{Use of Patented Materials and Processes}

Use of materials and processes as a research tool in the conduct of experiments is commonly referred to as research 'with' the invention and is generally regarded as a use that requires the prior authorisation of the patent holder (ACIP, 2005:6.1). For example, for many years, almost any new technology in the area of biotechnology required the use of the Cohen-Boyer patent on recombinant DNA. The owner required those using the patented 'research tool' technology to seek prior authorisation, but adopted a policy of wide licensing at a moderate fee (Monotti, 2003:6.84-6.85). Other well-known examples of research tools include polymerase chain reaction or PCR for the amplification of DNA or RNA sequences, DNA sequencing, expressed sequence tags (ESTs) and stem cell lines (Garde, 2005:273). Infringement is likely if the use of the materials or process is as a research tool, but may otherwise be uncertain while the complexities of the existence of an experimental use exemption remain unresolved. The risk of being accused of infringement is high where there are patents that are an essential requirement for the development of products in a particular field of technology.

Patented materials or processes may also be supplied for the purposes of conducting research on the invention itself. This is commonly referred to as research on the invention as distinct from research with the invention and incorporates the types of conduct that are outlined below. (ALRC 2004; ACIP, 2006) Although the differences between the concepts of research on and research with an invention provide no clear distinction, there are certain common features of research that fall within the scope of research on the invention, namely:

(a) Testing an invention to determine its sufficiency or to compare it to prior art. This includes tests to see whether a patentable invention falls within the scope of an existing patent; 
(b) Tests to determine how the patented invention works. Here, the tests may involve use of patented product as an object of scientific investigation or experimentation. They enable the validity of existing patents to be properly tested by experimentation.

(c) Experimentation on a patented invention for the purpose of improving on it, to develop a further patentable invention or to advance the technical field of the invention through new knowledge relating to the invention.

(d) Experimentation for the purpose of 'designing around' a patented invention.

There is no agreement on which, if any, of these uses of a patented invention infringe the patent holder's exclusive rights to exploit the patent (ALRC, 2004; ACIP, 2006; Monotti, 2006a). Here, the nature of the use becomes relevant to the risk management procedures that universities must apply and to their ability to issue clear guidelines for compliance with NP5. The extent of informal sharing of materials presents them with difficulties and exposes them to potential claims from patent holders if the uses are found to infringe their exclusive rights. The need for risk management procedures to minimise informal sharing of materials (some of which may be the subject of patent rights) intensifies when research is conducted using funding from national competitive grants.

A further problem for universities is how they educate researchers to be aware of this issue. The Monash Survey suggested that there was a degree of ignorance as 33 of 87 respondents who received tangible research materials without an MTA didn't know whether the material should have been supplied under an agreement.

\section{Procedures for Clearing Freedom to Use in Universities}

It is clear that most universities have procedures in place to encourage invention disclosures. These procedures are set out usually in the relevant intellectual property statute or policy. Appropriate inquiries and database searches would be performed for any disclosed invention that was thought to be worthy of patent protection. However, it is not known what procedures apply for undertaking an FTO analysis prior to an application for a national competitive grant or prior to research commencing once the grant is successful. Inquiries at Monash suggest that an FTO analysis might be likely to occur where an ARC Linkage Grant is concerned. Here, researchers will have a reasonable idea of the work in their area and may do some database searching prior to putting in the grant application. They would be counselled by business development managers to do these searches on the basis that there is no point spending money on research if they cannot exploit it because of existing prior art. However, there is no procedure for a routine FTO analysis to comply with NP5 because this requirement is not something that is known or understood by the people at Monash to whom the author spoke. Also, the application forms for an ARC Linkage Grant inquire as to whether the Administering Organisation has arrangements to manage intellectual property and to facilitate commercialisation of research but make no inquiry as to 
freedom to operate. Business development managers are not concerned with noncommercial grants such as the ARC discovery grants so any FTO analysis would occur randomly and at the behest of the individual researchers.

It is not known what procedures universities or individual researchers follow to protect against unauthorised uses of patented materials as research tools. Nor is it clear what procedures a university could or should follow in this regard, and particularly where the risk arises from informal exchange of materials. Some universities and most of industry in the US have apparently developed working solutions to the issue of access to patented research tools where licences are not possible. These include inventing around the patents, going offshore, building and using public databases, court challenges, flying under the radar, a research tool registry, consortia, clearing houses and patent pools (Buck, 2005).

\section{Compliance with NP5}

Compliance with NP5 may require researchers to voluntarily delay the acceptance of an informal exchange of materials to enable a freedom FTO analysis to be performed. It may also require researchers to await the successful negotiation of an MTA or to make inquiries and conduct relevant database searching. Some delay is justified when the use of the invention would otherwise infringe a patent. The critical issue for universities here is to have efficient, practical and realistic practices that minimise delay, in the hope that most researchers will appreciate the need to resolve these matters before research commences or proceeds too far. Unfortunately, to some extent the lack of model agreements restricts their ability to streamline practices (Monotti, 2006b). The difficulties are exacerbated when researchers can obtain what they need through informal exchanges.

There is good reason why FTO analysis in the research phase should be selective rather than obligatory. Anecdotal evidence suggests opposition to more regulation in this area, so it is important to design any FTO procedures with an eye to their likely acceptance by researchers. In the context of access to biomedical materials, some respondents to the Monash Survey commented as follows:

All of our research is subject to ethics committee review. We provide human tissue samples, with consent, for research at another institution the only motivation is really goodwill and relationship building. At times we are provided with clinical data by others which is used to obtain sufficient sample size for meaningful analysis. It will be a sad day if profit/contract, and lawyers, intrude on these arrangements.

I think we should emphasise universal access not restriction because that will make the benefits of research widely available.

Yes. Lawyers should stay out of this area. There is already too much wretched bureaucracy taking up our time and energy. The last think we want is more. The current system of informal exchange works well for us, and I'd hate to see it formalised. 
Costs and bureaucracy imposed by Australian Quarantine and Inspection Service need to be addressed urgently.

The Monash Survey results may not be representative or indicative of what happens elsewhere, particularly in view of the small sample, but they illustrate some of the problems that could arise if universities attempt to enforce FTO analysis before the commencement of research. Another reason for selectivity in FTO analysis is the need to avoid unnecessary delays in the commencement and conduct of research. Delay was certainly an irritant to some respondents to the Monash Survey 2005 who used or had used materials supplied to them under the terms of an MTA. They were asked two preliminary questions.

The first question was: 'Has your research been adversely affected by access to Materials?' Of 82 of the 122 respondents who answered this question, 34 percent answered yes. Therefore, a clear majority of respondents to this survey did not identify access to tangible research materials as having an adverse effect upon their research. Nevertheless, a significant minority of 34 percent of these respondents did identify this consequence. The representation of these positive responses came from respondents in the following classes of appointment: professors (2 of 11), Associate Professors (3 of 10), Postdoctoral Fellows (11 of 21), Research Fellows (9 of 25) and Senior Lecturers (3 of 11).

The second question related specifically to the effect of any conditions in an agreement. This question asked: 'Have conditions been imposed on access that caused you frustration and/or adversely affected your research?' Of the 82 respondents who answered this question, 36 percent answered yes. Although the majority of respondents did not identify delays as problematic, the level of frustration that the survey results disclose does not engender confidence in the successful operation of a system that would ask researchers to voluntarily delay the acceptance of an informal exchange of materials to enable an FTO analysis to be performed. For example, one respondent commented that a delay of three weeks in completing and posting out a signed MTA 'simply doesn't allow my research to be competitive enough.' As further evidence of the frustration that delays can cause, a small number of respondents admitted that they had agreed to conditions in an MTA for the supply of materials against advice.

\section{Impact of Lack of a Clear Research Exemption}

As compliance with the National Principles arises as a term of the funding contract, there is no obligation to comply with NP5 prior to a grant application. Instead, universities must clear the path for future commercialisation of publicly funded research of the kind that the NHMRC and the ARC supports before the research commences but after that research is funded. Leaving aside the matter of use of patented materials as research tools which will infringe the patent holder's rights, how do universities comply with this obligation when the freedom to use patented inventions in research is so uncertain? It is dangerous for them to promulgate policies that advise researchers that they can use patented inventions 
in their research without infringement provided that the use is not for commercial advantage. Similarly, it is unwise to promulgate a narrower version of the possible scope of exempted uses as this may inhibit research that is not infringing.

\section{Timing of Compliance with NP5}

The obligation to comply with NP5 before the research commences makes sense if all funded research were commercially driven. Already, Monash has procedures in place to perform necessary FTO searches when inventors disclose inventions that may be patentable. In addition, business managers can assist scientists to assess if their invention is already covered by a patent. This type of assistance occurs generally during the course of the research and not at or prior to a grant application. Nevertheless, there are exceptions, and some researchers who are commercially driven have asked for searches before embarking on experiments but not before grant application. But this is the exception rather than the rule.

The reality is that much university research is of a fundamental nature. Researchers may be aware of competitors in their field but not necessarily of the existence of patents. Therefore, there are problems with the imposition of an obligation in the form of NP5 prior to commencement of research. First, it seems to impose on universities a higher standard of vigilance than may apply in parts of the commercial sector. All researchers would need to do patent searches on any reagent, technique, gene sequence, protein or animal they might use, do an FTO analysis and then negotiate licenses whenever a relevant patent is discovered.

Second, although government policy clearly directs universities to exploit intellectual property commercially, most of the research done with this type of funding will not be commercial. The research outcomes will be principally in the nature of publications, teaching and training. Hence, it is difficult to justify expending public funds on searching patent databases if its purpose is to establish freedom to operate. Such an analysis requires considerable skills that researchers may not possess and universities are unlikely to have the practical or financial capability to engage in 'risk management' to this extent for every research project that their researchers conduct. It is likely that the results of FTO analysis could have an impact upon the cost of the research without a corresponding benefit, if the extent of informal sharing of materials is widespread. It may also affect the fields in which research is pursued and could result in researchers having to modify their funded projects. It is difficult to see how a university could comply with these administrative and financial obligations in the way that NP5 requires without injection of substantial resources. These adverse consequences increase if universities believe that there is no experimental use exemption at common law.

Third, where research projects have no commercial funding or involvement, it is possible that researchers could view this obligatory FTO analysis prior to commencing research as an intrusion by government upon academic freedom to choose their area of research without interference.

A consideration of these possible consequences of NP5 compliance after funding but before research commences raises the issue of the intended purpose of 
compliance with NP5. Freedom to operate is of critical importance in any proposed commercial development of intellectual property. However, is it also the purpose of NP5 to clear the way for the initial research before any commercial outcomes are evident? In the absence of NP5, universities can manage their risk in a realistic way not requiring such pro-active FTO analysis before research commences. A number of strategies are available to patent holders suspecting infringing uses of their inventions and they will continue to exercise them in a manner appropriate to their interests. There is evidence that many patent holders raise no objection to infringing uses for pragmatic or commercial reasons, some of which were identified in Genes and Ingenuity. Research may add value to the invention, and hence benefit the patent holder, or enforcement may not be practical (ALRC, 2004:13.39). Others may seek to exploit a lucrative market of which they were formerly oblivious. The obligations under NP5 may place a burden on universities to act as the de facto agents of the patent holders, a burden that commercial enterprises would assume only after a cost-benefit analysis.

A more important but related purpose of investigating existing intellectual property in the proposed field of research concerns the identification of the research questions that require answers. Researchers generally obtain their knowledge of the state of the art from publications and conference presentations. A survey of 414 US biomedical researchers in universities, government and nonprofit institutions found that few academic bench scientists pay much attention to other people's patents. Only 5 percent (18 of 379) regularly check patents for knowledge related to their research (Walsh, 2005). However, published patent specification databases world-wide, as well as commercial databases that add value to the raw data, provide a further valuable source of knowledge on the state of the art in particular fields of research. Therefore, in areas of heavy research and patenting activity, it would seem sensible to search these databases before researchers design and submit any grant application.

\section{Review of National Principles}

The terms of reference for the ALRC inquiry that resulted in its report Genes and Ingenuity included the examination of 'the impact of current patenting laws and practices related to 'genes and genetic and related technologies' on the application and commercialisation of research' (ALRC, 2004:Ch 11). An important part of that inquiry concerned whether the public funding agencies should have rights to any resulting intellectual property. This issue is not relevant in the context of this article (Productivity Commission, 2006). However, it is worth noting that neither the ARC nor the NHMRC assert rights to own any intellectual property that arises with the use of their funding. Moreover, they have no desire to do so (ARC, 2000:5). What is relevant concerns recommendations for review of the National Principles. The ALRC made the following recommendations:

Recommendation 11-1: The Australian Research Council (ARC) and the National Health and Medical Research Council (NHMRC) should 
review the National Principles of Intellectual Property Management for Publicly Funded Research (National Principles) to ensure that publicly funded research, where commercialised, results in appropriate public benefit. (See also Recommendations 12-1 and 17-2.)

Recommendation 11-2: The ARC and NHMRC should develop guidelines to assist organisations receiving public funding for research in complying with the National Principles. The guidelines should, among other things:

(a) provide guidance on what is meant by 'public benefit';

(b) assist organisations in determining whether it is appropriate for particular research results to be commercialised; and

(c) identify a range of approaches to the exploitation of intellectual property and the circumstances in which they might be used.

Recommendation 11-3: In exceptional circumstances, where the public benefit would clearly be served by broad dissemination of the results of publicly funded research, the ARC and the NHMRC should consider attaching conditions to the grant of funding. These conditions might include a requirement that research results be placed in the public domain, or that a patented invention be widely licensed.

Any review of these principles should also include NP5 and the purpose it seeks to achieve. At the same time, the ARC, NHMRC and other funding bodies could review the role that searches of published patent specification databases world-wide may have upon the research projects that they fund.

\section{Concluding Comments}

There is little formal precautionary behaviour that university-policy makers can use to minimise risks of patent infringement arising from the uncertain existence of an experimental use exemption. This is for two reasons. First, the lack of certainty in the scope of the patent holder's exclusive rights that has emerged with Patents and Experimental Use and Genes and Ingenuity, and submissions to those inquiries, suggests that it would be imprudent for a university to design formal policies that deal with the potential for research to infringe patents. While there is the possibility that research activities may infringe patents, it is equally possible that they are outside the scope of the patent holder's rights (Monotti, 2006a).

Second, there is a lack of evidence that patent holders more generally are actively enforcing rights against researchers and the lack of evidence that research is being impeded by present research practices means that there is no practical reason or incentive for most universities to alter current practices. Although Genetic Technologies Limited (undated), the owner of various patents that are of use in research, is imposing some pressure on individual universities, this is not the usual approach that patent holders take at present. The ACIP inquiry was set up at a time when there were fears of patent rights inhibiting research and 
development, particularly in biotechnology. There was concern that lack of clarity on whether an experimental use constitutes an infringement was affecting the general balance between incentives for innovation and the ability to use innovations. However, neither Patents and Experimental Use nor Genes and Ingenuity found evidence of this. Premature policies may result in the very problems with research that these inquiries failed to verify. Hence, universities must be cautious before writing a policy that purports to explain to researchers the extent to which they are free to experiment, research and engage in instructional activity without infringing the exclusive rights of the patent holder. The doubt as to the existence of an experimental use exemption at common law is unfortunate. However, the continuing uncertainty leaves universities little alternative but to await legislative change while managing risk from individual cases when it arises.

The greater complexities arise where research has funding from the ARC, NHMRC or other national body because universities must comply with the National Principles as a condition of the grant. In these cases, a university must contend with not only the risks associated with infringing the patent laws but also with NP5 and the risks of non-compliance with the conditions of the grants. Those conditions appear to require FTO analysis after the grant is approved but before the research commences. It is not clear how a university is expected to comply with NP5 in this early research phase, when much of the research will have no commercial outcome. Moreover, it is not clear whether NP5 was really intended to operate in this manner, as the emphasis in the National Principles is upon commercial exploitation of research. The above discussion suggests that the provisions of NP5 warrant a review. In the meantime, universities are wise to review, and if necessary, upgrade internal practices for practical risk management as a way of dealing with the obligations that NP5 imposes.

It is recommended that universities, the ARC and other national research councils should be proactive in initiating a review of NP5 and its intended purpose in conjunction with universities. As Chapter 11 of the Genes and Ingenuity report contains a number of recommendations for a review of the National Principles from another perspective, it would be appropriate to include NP5 within any review that takes place in response to those recommendations.

\section{References}

Advisory Council on Intellectual Property (2004), Patents and Experimental Use: Issues Paper, Australian Government, Canberra.

Advisory Council on Intellectual Property (2005), Patents and Experimental Use, Report, Australian Government, Canberra.

Auchard, E. (2005), 'Patent pact offers Linux protection’, The Australian, 11 November.

Australian Law Reform Commission (2004), Genes and Ingenuity: Gene Patenting and Human Health, Report, Australian Government, Canberra.

Australian Research Council, The Australian Tertiary Institutions Commercial Companies Association, The Australian Vice-Chancellors' Committee, The Department of Education, Training and Youth Affairs, The Department of Industry, Science and Resources, IP 
Australia and The National Health and Medical Research Council (2001), National Principles of Intellectual Property Management for Publicly Funded Research, Australian Government, Canberra.

Blanco White, T. (1974), Patents for Inventions and the Protection of Industrial Designs, 4th edn, Stephens \& Sons, London.

Buck, M. (2005), ‘No Exception?’, Pharmaceutical Executive May:66-68.

Burrone, E. (undated), 'New Product Launch: Evaluating your Freedom to Operate', http://www.wipo.int/sme/en/documents/freedom_to_operate.html.

Dennis, C. (2003), 'Geneticists Question Fees for Use of Patented “Junk” DNA', Nature 423(6936):105

Garde, T. (2005) 'Supporting Innovation in Targeted Treatments: Licenses of Right to NIH-Funded Research Tools', Michigan Telecommunications and Technology Law Review 11:249-284.

Genetic Technologies Limited (undated), http://www.gtg.com.au/ visited 22 June 2006.

Lahore, J. Dwyer, J. W. and Dufty, A. (1996 -), Patents Trade Marks and Related Rights, Butterworths, Sydney.

Master Agreement regarding use of the Uniform Biological Material Transfer Agreement (March 8, 1995), available at http://ott.od.nih.gov/NewPages/UBMTA.pdf.

Monotti, A. (2006a), 'Limitations on the Scope of a Patentee's Exclusive Rights in the Context of Third Party Experimental Uses', University of NSW Law Journal 29(2):63-87.

Monotti, A. (2006b), 'Access to Tangible Research Materials in Biomedical Research: Conditions of Access and their Effect on Research', Journal of Law and Medicine 14(1):86-101.

Monotti, A. and S. Ricketson (2003), Universities and Intellectual Property: Ownership and Exploitation, Oxford University Press, Oxford, UK).

Nicol, D. and J. Nielsen (2003), 'Patents and Medical Biotechnology: An Empirical Analysis of Issues Facing the Australian Industry', Centre for Law and Genetics, Occasional Paper No. 6.

Productivity Commission (2006), Public Support for Science and Innovation, Draft Research Report, Canberra.

National Institutes of Health (1998), Report of the Working Group on Research Tools, available at www.nih.gov/news/researchtools/.

Ricketson, S. (1984), The Law of Intellectual Property, The Law Book Company, Sydney.

Uniform Biological Material Transfer Agreement (UBMTA) and Implementing Letter, available at http://www.techtransfer.harvard.edu/MTA-UBMTA.html.

Walsh, J., C. Cho and W. Cohen (2005), 'View from the Bench: Patents and Material Transfers', Science 309:2002-2003.

I acknowledge the Australian Research Council support for this research. I thank the two anonymous referees for their comments on an earlier version. 